\title{
Implication of Sphingosine-1-P/Sphingosine Kinase Pathway in Non-alcoholic Fatty Liver Disease
}

\author{
Amira M Badr ${ }^{1,2}$, Yieldez A Bassiouni ${ }^{1,3}$ and Iman Alqarni ${ }^{1}$ \\ ${ }^{1}$ Department of Pharmacology and Toxicology, King Saud University, Saudi Arabia \\ ${ }^{2}$ Department of Pharmacology and Toxicology, Ain Shams University, Egypt \\ ${ }^{3}$ Department of Clinical Pharmacology, Alexandria University, Egypt \\ Submission: May 22, 2019; Published: May 31, 2019
}

"Corresponding author: Amira Badr, Department of Pharmacology and Toxicology, College of Pharmacy, King Saud University, P.O. Box 22452, 11459 Riyadh, Saudi Arabia

\begin{abstract}
Non-alcoholic fatty liver disease (NAFLD) is by far the most common cause of chronic liver diseases and is recently increasing in parallel with the epidemics of obesity and type II diabetes melitus [1]. Recent evidence has emerged of the possible implication of Sphingosine-1-P/ Sphingosine Kinase Pathway in NAFLD. Thus, better understanding and modulation of this pathway may play a potential role in the management of NAFLD.
\end{abstract}

Keywords: Non-alcoholic fatty liver; Sphingosine; Sphingolipids; Sphingosine-1-phosphate; Sphingosine Kinase; Adipocytokine imbalance; Mitochondrial dysfunction; Pro-fibrogenic mediators; Pro-inflammatory mediators

Abbreviations: NAFLD: Non-Alcoholic Fatty Liver Disease; IR: Insulin Resistance; C: Total Cholesterol; TG: Triglycerides; SIP: Sphingosine1-Phospate; SPK: Sphingosine-Kinase; IL: Interleucin; NASH: Non-Alcoholic Steatohepatitis; TIRAP: TIR Domain-Containing Adaptor Protein

\section{Introduction}

Human non-alcoholic fatty liver disease (NAFLD) is complex where multiple factors acting in parallel in genetically predisposed individuals lead to the development and progression of the disease. Imbalanced lipid metabolism and insulin resistance (IR) are considered as the "first hit, subsequently, the liver becomes vulnerable to other hits involving adipocytokine imbalance, mitochondrial dysfunction, gut-derived bacterial endotoxemia and release of pro-inflammatory and pro-fibrogenic mediators from the impaired organelles [1,2].

Sphingosine1-phosphate (S1P) is a potent bioactive sphingolipid metabolite that regulates diverse cellular processes that are important for inflammation and immune responses. S1P is generated by sphingosine kinases (SphK) 1 and/or 2 from sphingosine which is an intermediate of the ceramide metabolism [3]. Extracellular S1P binds to five high-affinity G protein-coupled receptors
(S1PR) with subsequent generation of multiple downstream signals that play essential roles in cell proliferation, differentiation, angiogenesis, inflammation and malignant transformation [4].

Numerous agonists activate SphK1, including growth factors, hormones, pro-inflammatory cytokines and lipopolysaccharides. SphK1 and S1P are necessary for the phosphorylation of IkB $\alpha$ and nuclear factor-kB (NFkB) activation, Figure 1. Impairment of SphK1/S1P signaling pathway may be a risk factor for impaired insulin signalling which in turn results in over-production and secretion of triglycerides (TG), total cholesterol (C) and very low density lipoprotein by the liver of high fructose-fed hamsters [5] and rats [6]. Deletion of S1P-lyase which catalyses the irreversible degradation of S1P increases the levels of S1P as well as TG, diacyl glycerol and $\mathrm{C}$ in murine liver, indicating a role of the sphingolipid pathway in general lipid metabolism [7]. 


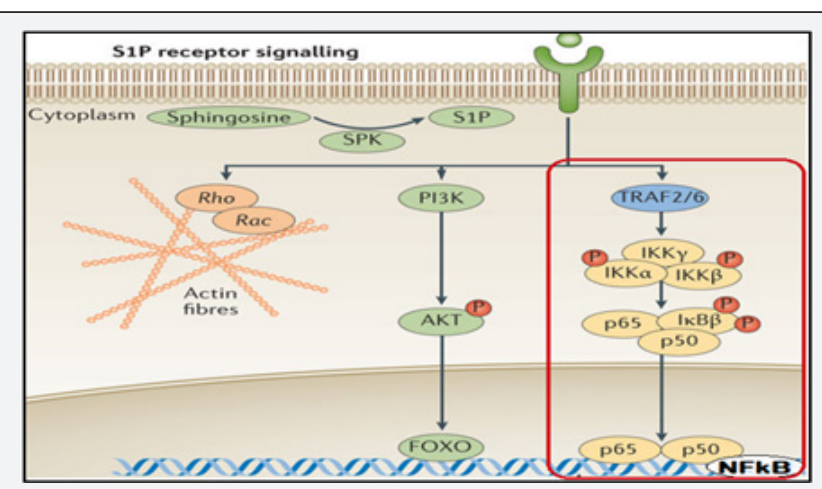

Figure 1: Sphingosine-1-phospate (SIP) is formed through the phosphorylation of sphingosine by sphingosine-Kinase (SPK). Binding of S1P to its receptors activates a number of signaling molecules. TNF receptor-associated factor $2 / 6$ (TRAF2/6) is an adaptor protein implicated in the regulatory ubiquitination of RIP1 that phosphorylates lkk leading to the transcription of NFKB. Figure is adapted and modified from Tas et al. [8].

\section{Role of S1P/SPK Pathway in Development of NAFLD}

Researchers have reported 2-folds elevation of SphK1 in livers of NAFLD patients [9]. Of importance, Wang et al. investigated the role of hepatic SphK1/S1P signaling pathway in high fructose-fed rats and reported that fructose feeding induced hyperlipidemia, activated SphK1/S1P signaling pathway, elevated SphK1 activity and S1P production which in turn activated NFKB signaling with subsequent production of interleucin (IL)-1, IL6 and TNF $\alpha$ leading to liver inflammation [10]. Also, it was found that overexpression of exogenous acid sphingomyelinase which catalyses the breakdown of sphingomyelin to ceramide in mice resulted in hepatic steatosis, which was blocked by SphK1 deletion, suggesting a pro-steatotic role of SphK1 [11].

Another study revealed that SphK1 was induced both in primary hepatocytes and in vivo in human non-alcoholic steatohepatitis (NASH) and in a mouse NASH model under overload of saturated fatty acids (e.g., conditions which occurs with MetS). The induction of SphK1 and synthesis of S1P lead to the production of pro-inflammatory cytokines. In isolated hepatocytes, the activated $\mathrm{S} 1 \mathrm{P}$ receptors promoted the activation of NFKB-dependent inflammation and mediated crosstalk with HSC to activate the pro-fibrotic programs [12]. Thus, it is believed that increased lipids cannot lead to steatohepatitis unless inflammatory pathways are activated. As sphingolipids can activate inflammatory mediators, they are strongly implicated in the transition of simple benign fatty liver to the more concerning NASH [13]. Recently, Alqarni et al. [14] found that S1P and SPK were upregulated in high fructose fed rats, and this was associated with increased expression of S1PR1 and S1PR3. The increased expression of S1p/SPK was correlated with increased expression of NF-kB and Toll-4 (TLR4) receptors, supporting a cross talk of S1P/SPK pathway and TLR4/NF-kB pathway. This crosstalk was previously reported in other tissues. S1P has been shown to enhance the protein kinase required by TLR-dependent NFKB activation which plays a key role in the onset of local inflammation [15], Figure 2. Telmisartan, one of the drugs used for treatment of NAFLD, mediated its effect partially by inhibiting of S1P/SPK pathway [14].

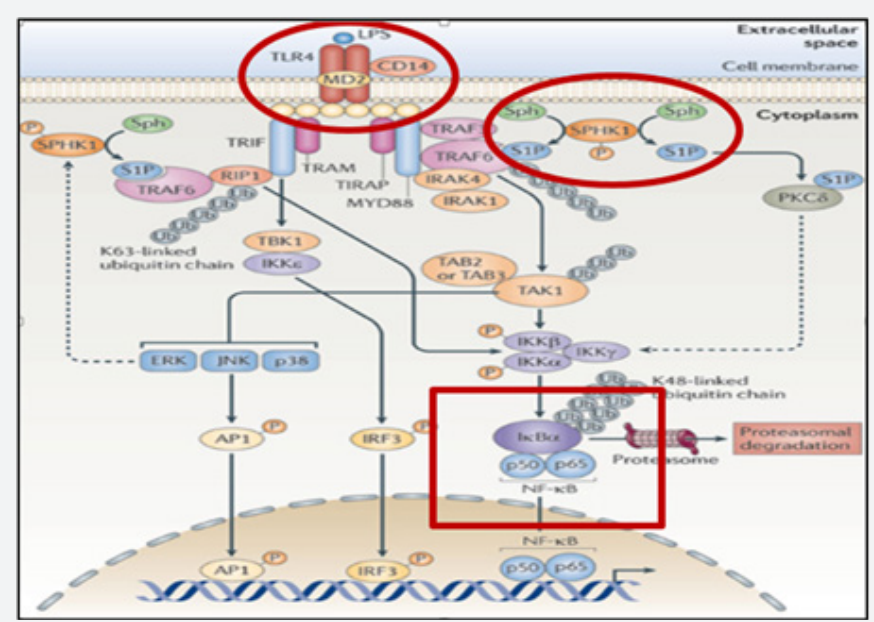

Figure 2: Binding of LPS to TLR4 at the plasma membrane promotes the recruitment of the adaptor myeloid differentiation primary response protein 88 (MYD88) and the assembly of a signaling complex that includes another adaptor called TIR domaincontaining adaptor protein (TIRAP) and TNFR-associated factor 6 (TRAF6). TRAF6 activates TAK with subsequent activation of IKK and NFKB transcription. On the other hand, S1P binds to S1P receptor and enhances NFKB activation through phosphorylation of IKK by the autoubiquitination of TRAF6. Figure is adapted and modified from Spiegel \& Milstien [16]. 


\section{Conclusion}

So, collectively dysregulation of S1P/SPK pathway is probably implicated in development of liver diseases, particularly NAFLD, and thus, modulation of such pathway can help to mitigate development and progression of NAFLD [17].

\section{References}

1. Kapravelou G, Martínez R, Nebot E, López-Jurado M, Aranda P, et al (2017) The combined intervention with germinated vigna radiata and aerobic interval training protocol is an effective strategy for the treatment of non-alcoholic fatty liver disease (NADLD) and other alterations related to the metabolic syndrome in zucker rats. Nutrients 9(7): 774

2. Day C, James O (1998) Steatohepatitis: a tale of two "hits". Elsevier.

3. Ebenezer D, Fu P, Natarajan V (2016) Targeting sphingosine-1phosphate signaling in lung diseases. Pharmacol Ther 168: 143-157.

4. Kowalski G, Kloehn J, Burch M, Selathurai A, Hamley S, et al. (2015) Overexpression of sphingosine kinase 1 in liver reduces triglyceride content in mice fed a low but not high-fat diet. Biochim Biophys Acta 1851(2): 210-219.

5. Tsai J, Zhang R, Qiu W, Su Q Naples M, et al. (2009) Inflammatory NF- $\mathrm{B}$ activation promotes hepatic apolipoprotein B100 secretion: evidence for a link between hepatic inflammation and lipoprotein production. Am J Physiol Gastrointest Liver Physiol 296(6): G1287-G1298.

6. Li J, Li Y, Kong L, Hu Q (2010) Curcumin inhibits hepatic proteintyrosine phosphatase $1 \mathrm{~B}$ and prevents hypertriglyceridemia and hepatic steatosis in fructose-fed rats. Hepatology 51(5): 1555-1566.

7. Bektas M, Allende M, Lee B, Chen W, Amar M, et al. (2010) Sphingosine 1-phosphate lyase deficiency disrupts lipid homeostasis in liver. J Biol Chem 285(14): 10880-10889.

8. Tas PW, Koschel K (1998) Sphingosine-1-phosphate induces a $\mathrm{Ca}^{2+}$ signal in primary rat astrocytes and $\mathrm{Ca}^{2+}$ signal and shape changes in C6 rat glioma cells. J Neurosci Res 52(4): 427-434.
9. Geng T, Sutter A, Harland M, Law B, Ross J, et al. (2015) SphK1 mediates hepatic inflammation in a mouse model of NASH induced by high saturated fat feeding and initiates proinflammatory signaling in hepatocytes. J Lipid Res 56(12): 2359-2371.

10. Wang X, Zhang D, Gu T, Ding X, Fan C, et al. (2013) Morin reduces hepatic inflammation-associated lipid accumulation in high fructosefed rats via inhibiting sphingosine kinase 1/sphingosine 1-phosphate signaling pathway. Biochem Pharmacol 86(12): 1791-804.

11. Osawa Y, Seki E, Kodama Y, Suetsugu A, Miura K, et al. (2011) Acid sphingomyelinase regulates glucose and lipid metabolism in hepatocytes through AKT activation and AMP-activated protein kinase suppression. FASEB J 25(4): 1133-1144.

12. Cowart L (2016) Sphingosine-1-Phosphate Signaling in Non-Alcoholic Steatohepatitis. FASEB J 30(1): 870-876.

13. Montefusco DJ, Allegood JC, Spiegel S, Cowart LA (2018) Non-alcoholic fatty liver disease: Insights from sphingolipidomics. Biochem Biophys Res Commun 504(3): 608-616.

14. Alqarni I, Bassiouni YA, Badr AM, Ali RA (2019) Telmisartan and/ or chlorogenic acid attenuates fructose-induced non-alcoholic fatty liver disease in rats: Implications of crosstalk between angiotensin, the sphingosinekinase/sphingoine-1-phosphate pathway and TLR4 receptors. Biochem Pharmacol 164: 252-262.

15. Schwalm S, Pfeilschifter J, Huwiler A (2014) Targeting the Sphingosine Kinase/Sphingosine 1-Phosphate Pathway to Treat Chronic Inflammatory Kidney Diseases. Basic \& clinical S pharmacology \& toxicology 114(1): 44-48.

16. Spiegel S, Milstien S (2011) The outs and the ins of sphingosine-1phosphate in immunity. Nat Rev Immunol 11(6): 403-415.

17. Kleuser B (2018) Divergent Role of Sphingosine 1-Phosphate in Liver Health and Disease. Int J Mol Sci 19(3).

\section{Your next submission with JuniperPublishers will reach you the below assets}

- Quality Editorial service

- Swift Peer Review

- Reprints availability

- E-prints Service

- Manuscript Podcast for convenient understanding

- Global attainment for your research

- Manuscript accessibility in different formats

( Pdf, E-pub, Full Text, audio)

- Unceasing customer service

Track the below URL for one-step submission

https://juniperpublishers.com/online-submission.php 